\title{
History of lung transplantation
}

\author{
Federico Venuta ${ }^{1}$, Dirk Van Raemdonck ${ }^{2}$ \\ ${ }^{1}$ Department of Thoracic Surgery, Policlinico Umberto I and University of Rome La Sapienza, Rome, Italy; ${ }^{2}$ Department of Thoracic Surgery, \\ University Hospitals Leuven and Department of Clinical and Experimental Medicine, KU Leuven University, Leuven, Belgium \\ Contributions: (I) Conception and design: All authors; (II) Administrative support: None; (III) Provision of study materials or patients: All authors; \\ (IV) Collection and assembly of data: All authors; (V) Data analysis and interpretation: All authors; (VI) Manuscript writing: All authors; (VII) Final \\ approval of manuscript: All authors. \\ Correspondence to: Federico Venuta, MD, PhD. Department of Thoracic Surgery, Policlinico Umberto I and University of Rome La Sapienza, Viale \\ del Policlinico 155, Rome 00161, Italy. Email: federico.venuta@uniroma1.it.
}

\begin{abstract}
Lung transplantation nowadays is a well-accepted and routine treatment for well selected patients with terminal respiratory disease. However, it took several decades of experimental studies and clinical attempts to reach this success. In this paper, we describe the early experimental activity from the midforties until the early sixties. The first clinical attempt in humans was reported by Hardy and Webb in 1963 followed by others with short survival only except for one case by Derom et al. who lived for 10 months. Long-term successes were not reported until after the discovery of cyclosporine as a new immunosuppressive agent. Successful heart-lung transplantation (HLTx) for pulmonary vascular disease was performed by the Stanford group starting in 1981 while the Toronto group described good outcome after single-lung transplantation (SLTx) for pulmonary fibrosis in 1983 and after double-lung transplantation for emphysema in 1986. Further evolution in surgical techniques and in transplant type for the various forms of end-stage lung diseases are reviewed. The evolution in lung transplantation still continues nowadays with the use of pulmonary allografts coming from living-related donors, from donors after circulatory death, or after prior assessment and reconditioning during ex vivo lung perfusion (EVLP) in an attempt to overcome the critical shortage of suitable organs. Early outcome has significantly improved over the last three decades. Better treatment and prevention of chronic lung allograft dysfunction will hopefully result in further improvement of long-term survival after lung transplantation.
\end{abstract}

Keywords: Lung transplantation; history; single-lung; double-lung; heart-lung

Submitted Sep 04, 2017. Accepted for publication Oct 20, 2017.

doi: $10.21037 /$ jtd.2017.11.84

View this article at: http://dx.doi.org/10.21037/jtd.2017.11.84

Lung transplantation nowadays is considered a viable therapeutic option for well selected patients with advanced respiratory disease. However, it took several decades of experimental studies and clinical attempts to reach this success. In fact, although the first human lung transplantation was performed more or less at the same time as other solid organs, with the exception of kidneys, its development to a routine procedure took longer than for other transplant types. The reasons for this delay were related to technical problems mainly involving healing of the bronchial anastomosis, to the high immunogenicity of the lung with need for immunosuppression, and the substantial risk of pulmonary infection.

\section{Early experimental activity}

The earliest attempt to transplant the heart and both lungs was performed by Alexis Carrel (Figure 1A) at the beginning of the $20^{\text {th }}$ century; however, this experimental procedure involved only heterotopic transplantation of the heartlung block into the neck of a recipient cat (1). In that model lung edema occurred with distention of the right side of the heart.

In the mid-forties the Russian surgeon Vladimir P. 

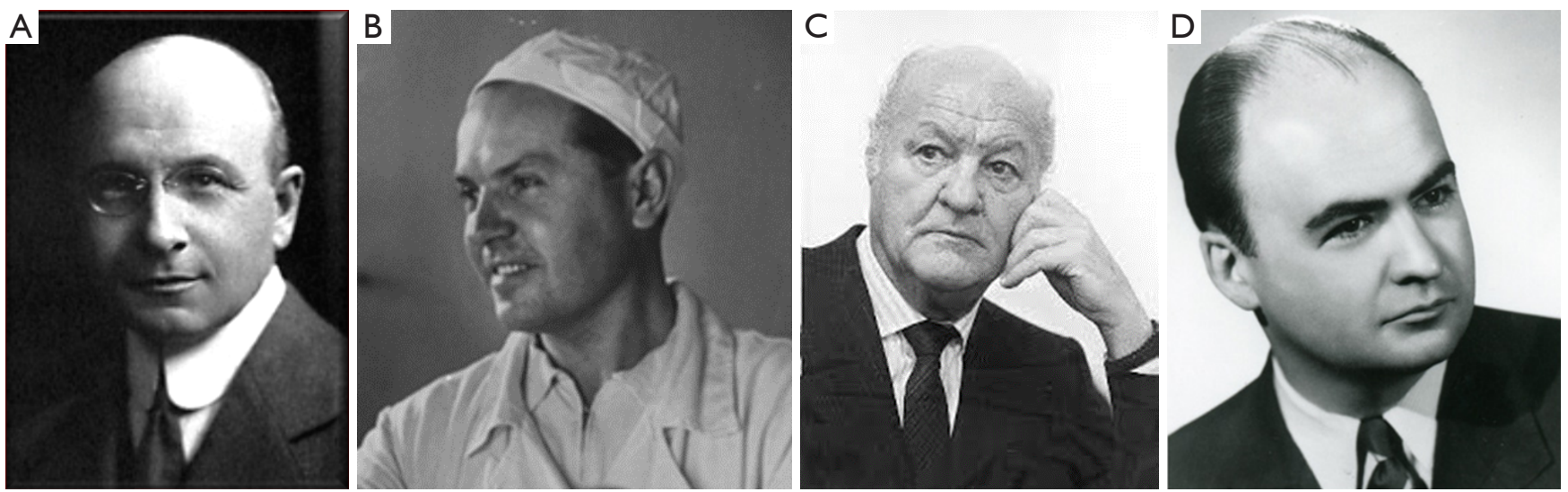

Figure 1 Pioneers paving the way to human heart \& lung transplantation. (A) Alexis Carrel at the time of his Nobel Prize presentation, 1912 (picture courtesy of the Nobel Foundation.); (B) Vladimir Demikhov (picture available at http://bored-bored.com/top-10-mad-scientistsin-history, accessed August 8, 2017); (C) Vittorio Staudacher; (picture courtesy by Dr. Luigi Santambrogio, Milan, Italy); (D) Henri Metras (picture available at http://patrimoinemedical.univmed.fr/rues/rues_metras.htm, accessed August 8, 2017).

Demikhov (Figure 1B) transplanted right lower lobes and the heart-lung block in dogs $(2,3)$. At that time cardiopulmonary bypass was not yet available; Demikhov developed a technique to maintain blood supply to the brain continuously, with the exception of $2-3$ minutes at one critical stage. The first animal recipient survived only for two hours without its organs; only after 1949 a more prolonged survival was obtained (3). Interestingly, the heartlung block was kept viable during transfer from the donor to the recipient animal by closed-circuit circulation with the heart beating and blood pumped from the left ventricle into the aorta and coronary vessels and into the right atrium, the right ventricle and pulmonary circulation; by means of this ex situ circuit oxygenated blood was returned into the left atrium and adequate supply to the coronary circulation could be maintained. This preparation was the basis of means of transporting and temporary preserving the heart and lungs after harvesting during the first clinical attempts of heart-lung transplantation (4). The vascular and tracheal anastomoses were performed either by continuous suturing or by "quick connects" over prosthetic tubes. The caval veins were sutured separately; during inferior caval vein anastomosis the blood supply to the inferior part of the animal body was interrupted for 15-20 minutes. There were 67 attempts, but only 6 dogs survived for more than 48 hours and only 2 for more than 4 days. The dogs that recovered after surgery showed a slow respiratory rate and fast cardiac rate; some of them did remarkably well, being able to walk, drink and eat.

At that time other authors performed experimental heart-lung transplantation (HLTx). Marcus and coworkers developed a technique to transplant the heart and both lungs into the abdomen, giving the recipient two sets of heart and lungs; the purpose of their experiment was to determine if the heterologous block could be used as an extracorporeal pump during intracardiac operations or to temporary decrease the work load to the native heart $(5,6)$. In 1950, Staudacher in Milan, Italy (Figure 1C) attempted canine lung transplantation using the right lower lobe and comparing for the first time autografts and allografts (7). Matejicek in 1956 reported a study on transplantation of the heart and the right upper lobe of the lung within the chest without mentioning any result (8).

Henri Metras in Marseille, France (Figure 1D) was the first to report in 1950 successful left lung transplantation in dogs (9). Interestingly, he was also the first to preserve and reimplant the bronchial arteries (to the subclavian artery) to immediately restore bronchial vascularization; he also described the use of a cuff of left atrium around the pulmonary veins to reduce the risk of venous thrombosis. In the early fifties, Juvenelle (10) and Neptune (11) performed lung autotransplantation in dogs to study the effects of denervation on lung physiology. In particular, Juvenelle in 1950 performed a pneumonectomy and reimplanted that lung by individual anastomosis of the bronchus and pulmonary artery and veins (10). Postoperative studies demonstrated vascular perfusion of the lung on the $18^{\text {th }}$ day by angiocardiography and good lung function. Neptune performed 25 left lung allotransplants with no longterm survivors. Howard and Webb demonstrated nerve 

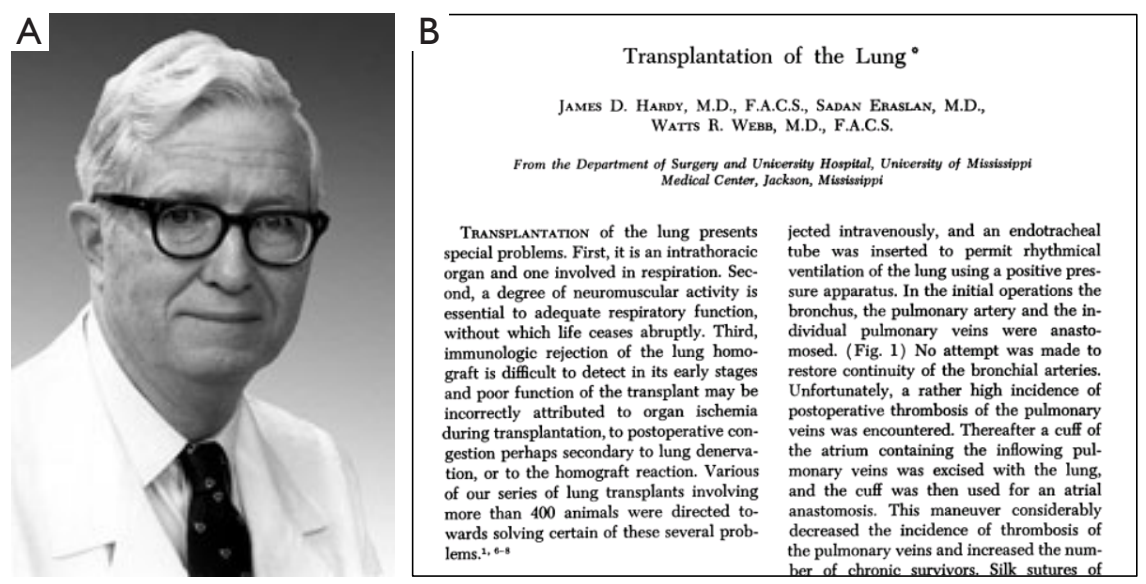

Figure 2 The first human lung transplantation was performed on June 11, 1963 at the University Hospital, Jackson, Mississippi by James D Hardy and his team. The donor died of massive heart attack resulting in heart failure and shock and was therefore the first non-heart-beating donor (NHBD), now named donor after circulatory death (DCD). A left SLTx was successfully performed. The recipient, the 58-year-old John Russell with an obstructive tumor in the left main bronchus died 18 days later from renal failure. (A) James D. Hardy (picture available at https://www.umc.edu/som/Departments\%20and\%20Offices/SOM\%20Departments/Surgery/Residents/About-Us/James\%20Hardy/ James-Hardy.html, accessed August 8, 2017); (B) Original paper as published in Ann Surg presented at the Annual Meeting of the American Surgical Association, Hot Springs, Virgina, April 1-3, 1964 (18).

regeneration microscopically $(12,13)$. In 1954 Hardin and Kittle reported their results with left lung allografts in dogs using the same atrial cuff technique as previously reported by Metras (14). This is the first report on living-related lung transplantation since in three transplants, donors were litter-mates. Survival was between 1 and 12 days, but it was 30 days in the living-related transplants. Pneumonia was the most frequent cause of death. In two cases they performed contralateral pneumonectomy immediately after the transplant; the animals survived 6 and 9 days proving the effective function of the pulmonary allograft.

In 1961 Blumenstock and Kahan demonstrated that methotrexate was helpful to increase allograft survival in dogs (15).

\section{Early clinical experience}

After 7 years of experimental research on hundreds of animals, Hardy and Webb at the University of Mississippi, Jackson obtained permission to perform lung transplantation in a human recipient with the following characteristics: the patient should have a potentially fatal disease; there should be a reasonable chance that he would benefit from the transplant; the removal of the patient's own lung should not result in the sacrifice of a significant amount of his own functioning lung parenchyma; the transplant would have been performed on the left side, since it was judged to be technically easier (16).

On April 15, 1963, a 58-year old man with left lung bronchial carcinoma was admitted at the University of Mississippi Hospital. He showed dyspnea at rest from advanced emphysema; he had borderline renal failure due to chronic glomerulonephritis. He also had obstructive pneumonia due to neoplastic occlusion of the left main bronchus. The indication for pneumonectomy was based on the proximal location of cancer within the bronchus; the impossibility to perform curative left pneumonectomy was related to respiratory failure; the indication for left lung transplantation was consequent (17).

At approximately $7.30 \mathrm{pm}$ on June 11, 1963, a patient entered the emergency room of the same hospital in shock due to massive myocardial infarction. All resuscitative efforts failed and the family allowed donation of the left lung for transplantation. This was the first non-heart beating donor used for lung transplantation. Left lung transplantation was performed successfully by James D. Hardy and his team (Figure 2). The new lung worked properly for the subsequent 18 days. At that time immunosuppression was based on the administration of azathioprine and prednisone, and it included mediastinal irradiation. The patient survived 18 days and died of renal failure and infection. At autopsy, the lung was well ventilated and there was no evidence 

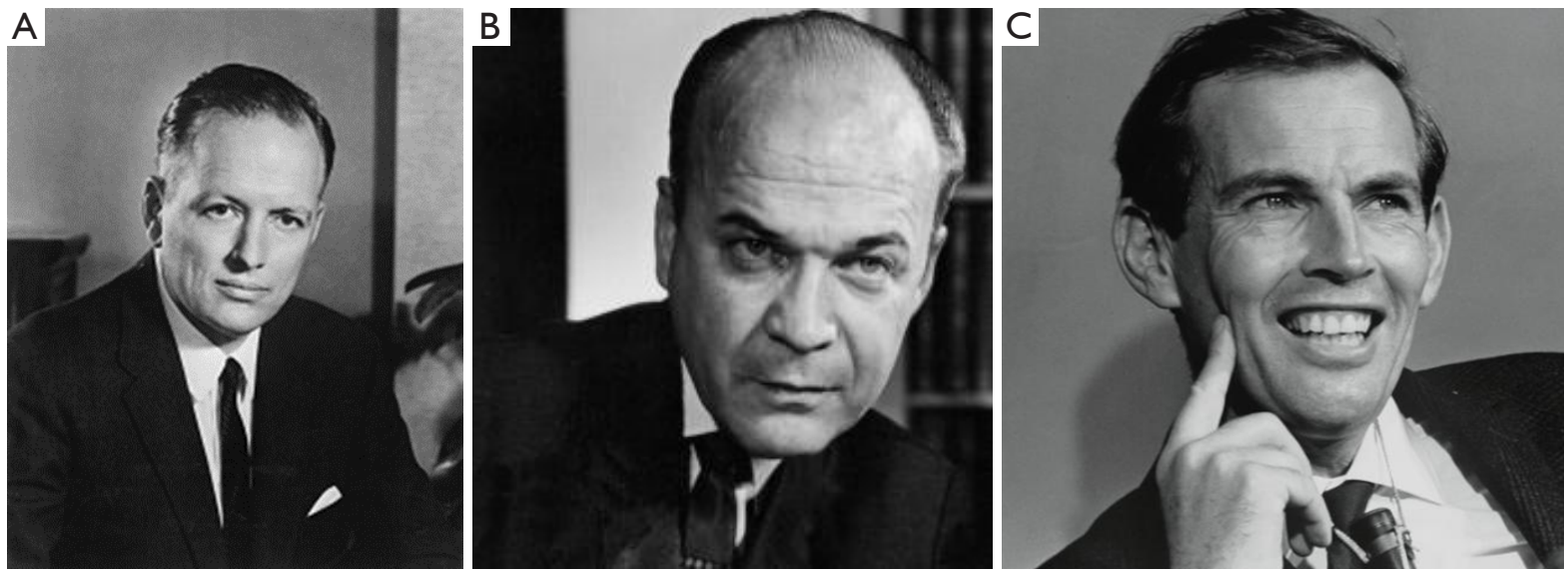

Figure 3 Three pioneers of human heart-lung transplantation. (A) Denton Cooley, Houston, Texas, 1968 (picture available at http://www. hopkinsmedicine.org/news/media/releases/pioneering_heart_surgeon_denton_a_cooley_dies_at_96, accessed August 8, 2017); (B) Walton Lillehei, University of Minnesota, Minneapolis, 1969 (picture available at http://www.thefamouspeople.com/profiles/clarence-waltonlillehei-5381.php, accessed August 8, 2017); (C) Christian Barnard, Grote Schuur Hospital, Cape Town, South Africa, 1971 (picture available at https://alchetron.com/Christiaan-Barnard-750845-W, accessed August 8, 2017).

of rejection; the vascular anastomoses were patent; the bronchus showed a small defect on the membranous side, but it was sealed by the inflammatory reaction of the surrounding tissues (18).

On August 31, 1968, Denton Cooley (Figure 3A) performed in Houston, Dallas the first HLTx in a 2-month old infant with a complete atrioventricular canal defect, pulmonary hypertension, and pneumonia (19). The child was reoperated for bleeding and died 14 hours after the transplant. The second HLTx was performed by Walton Lillehei (Figure 3B) in December 1969, in a 43-year-old patient with emphysema and pulmonary hypertension; he survived 8 days and died of pneumonia (20). The third HLTx was performed in July, 1971 in Cape Town, South Africa by Christian Barnard (Figure 3C) (21), who previously reported the first heart transplant (22). At that time airway anastomosis was performed at the level of the bronchi, in an attempt to preserve blood supply to the recipient carina and cough reflex. This latter patient died on the $23^{\text {rd }}$ postoperative day with a bronchopleural fistula on the right side. Barnard performed a pneumonectomy on this side, but fatal septicemia eventually occurred.

Between 1963 and 1978 approximately 38 lung, lobe or HLTx had been attempted, with no long-term success (23). Only one patient was discharged from the hospital in 1968 (23), and only nine lived more than two weeks (24). The vast majority died in the third postoperative week from disruption of the bronchial anastomosis. For this reason interest in lung transplantation decreased for most of the 1970s. The only medium-term survival was in a patient transplanted by F. Derom in Ghent, Belgium (Figure 4A) on November 14, 1968 (25). The recipient was a 23-year-old man with silicosis (Figure 4B). Left lung transplantation was performed (Figure 5). He died of bronchopneumonia in the transplanted lung after 10 months; at histology there were no signs of acute rejection, but some lesions were compatible with chronic rejection. Since the right lung was completely fibrotic and shrunken, we can suppose that the patient had lived at least the last months on the grafted lung.

In 1978 the group in Toronto led with Joel Cooper performed right lung transplantation in a young man suffering of respiratory burns due to a house fire requiring mechanical lung ventilation (27). At that time membrane oxygenators were available at that center (28) and the surgeons believed that this support could improve the chances of success. That patient, notwithstanding maximum ventilatory assistance, had a $\mathrm{pCO}_{2}$ of $130 \mathrm{mmHg}$ and required the use of the membrane oxygenator before, during and for four days after the procedure. Interestingly, the transplanted lung was pretreated with cytotoxic drugs. Within two weeks after the transplant the ventilatory system could be discontinued and the patient become ambulatory. The patient died in the third postoperative week of disruption of the bronchial anastomosis.

At that time it became clear that the major determinant for the future success of lung transplantation was related to 

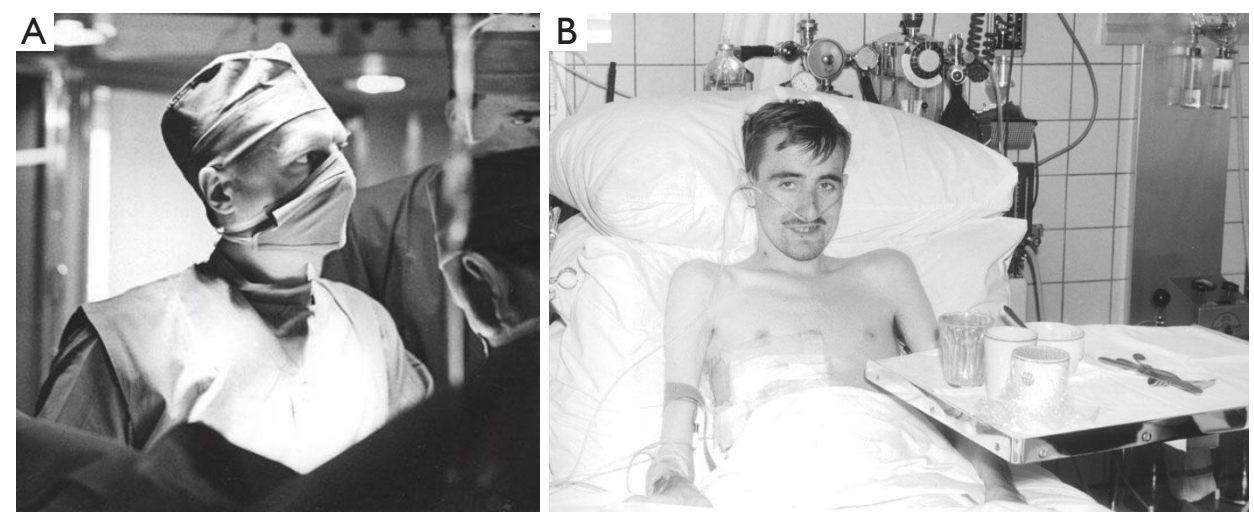

Figure 4 Lung transplantation: first mid term survivor in Belgium. (A) Prof. em Dr. Fritz Derom who performed a single-lung transplantation at the University Hospital in Ghent, Belgium on $14^{\text {th }}$ November 1968; (B) the patient Aloïs Vereecken became the first mid-term (10 months) survivor at the time (25). Pictures available at http://www.ugentmemorie.be/gebeurtenissen/1968-wereldprimeurlongtransplantatie, accessed August 8, 2017.

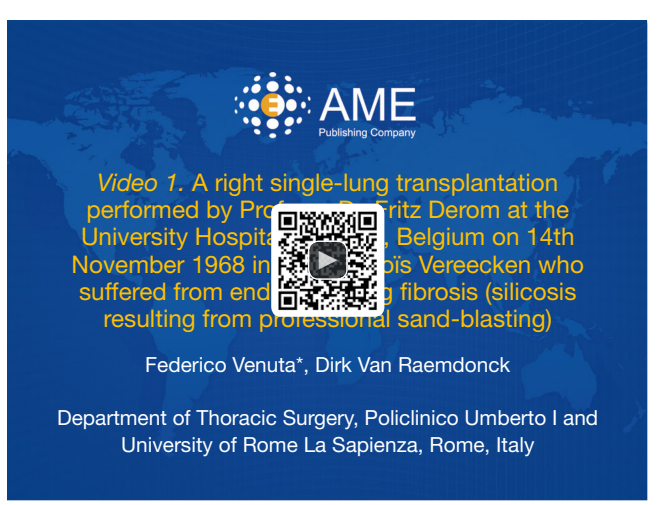

Figure 5 A right single-lung transplantation performed by Prof. em Dr. Fritz Derom at the University Hospital in Ghent, Belgium on 14th November 1968 in patient Aloïs Vereecken who suffered from end-stage lung fibrosis (silicosis resulting from professional sand-blasting) (26); (permission for reprint given by Fritz Derom at age of 90 years).

Available online: http://www.asvide.com/articles/1908

the establishment of an adequate bronchial arterial supply to the transplanted bronchus and the prevention of bronchial necrosis and disruption.

\section{Back to the lab}

The group in Toronto decided not to embark on further lung transplantation until they had gained better understanding of the cause of bronchial disruption and the means to prevent it. This is the reason why most of the animal laboratory research at that time has been done at their laboratories. Three factors were considered to be potentially related to bronchial dehiscence: rejection, ischemia (the lung is the only organ without systemic arterial vascularization routinely reimplanted at the time of transplantation), and immunosuppressive drugs (prednisone and azathioprine at that time).

The first series of animal experiments was dedicated to evaluate the potential role of rejection. These were based on autotransplantation of the lung in dogs. With this model factors associated with rejection were obviously eliminated. Half of the animals did not receive any immunosuppression while the other half received the same immunosuppressive regimen as if allotransplantation would be performed (29). Animals receiving no immunosuppression showed good primary healing of the anastomosis (only a degree of distal narrowing) while those receiving prednisone and azathioprine had the same incidence of bronchial complications as it had been observed in human transplants. Furthermore, in this group of animals, the breaking strength of the anastomosis was markedly reduced. At that time cyclosporine become available and the same experiment was repeated administering this drug instead of the association of prednisone and azathioprine (30). With cyclosporine, wound healing and breaking strength were not impaired. In subsequent studies prednisone and azathioprine were evaluated separately and the former was clearly responsible for the inhibition of bronchial healing (31).

Bronchial narrowing distal to the suture line was believed to be related to ischemia. To address this problem, the authors 

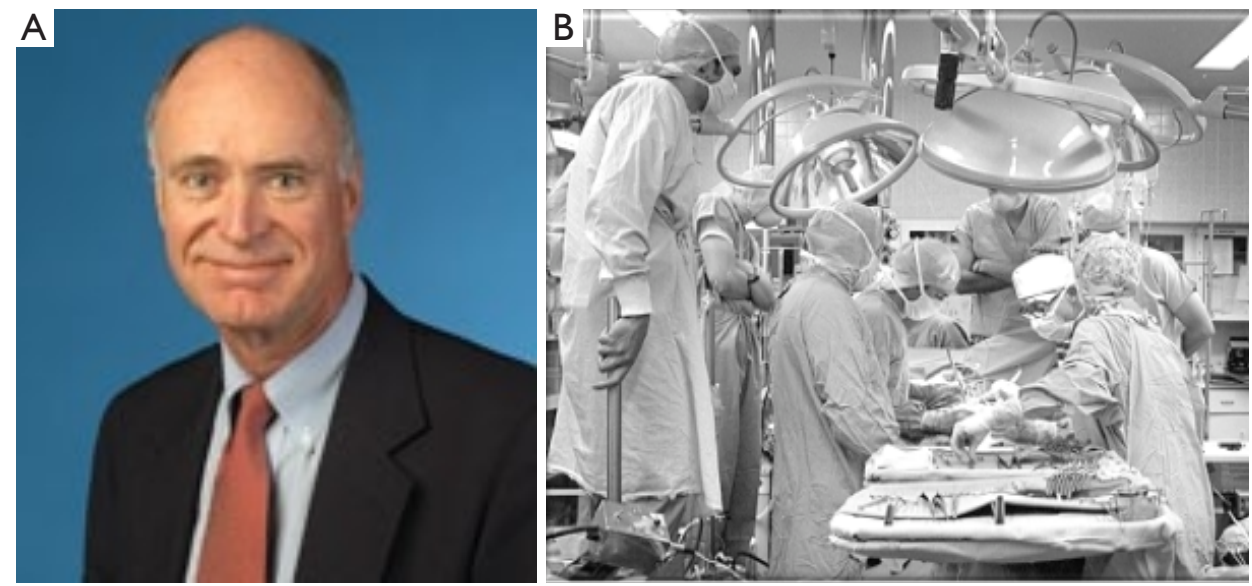

Figure 6 The first long-term success after human heart-lung transplantation was performed by Bruce Reitz and colleagues at Stanford University, Palo Alto, California, on March 9, 1981 (34). (A) Bruce Reitz; (B) picture taking in the operating room during transplantation. (pictures Stanford School of Medicine available at https://twitter.com/StanfordMed/status/707709259778269184, accessed August 8, 2017).

used the greater omentum. This organ was known for its ability to bring rapidly new blood supply when transposed into a potentially ischemic area. A new set of experiments were performed bringing the omentum into the chest and wrapping it around the bronchial anastomosis $(32,33)$. The animals were autopsied at various intervals after transplantation. In all the animals collateral circulation between the omentum and the airway at the level of the anastomotic site was observed. Normally, it takes between 2 and 3 weeks to restore a sufficient bronchial circulation by means of vascular growth.

Thus, changing the immunosuppressive regimen with the introduction of cyclosporine and protecting the bronchial anastomosis with a wrap of omentum, would certainly have contributed to prevent the dreadful complications that affected all the transplants previously performed.

\section{The new era}

A review of the literature showed that most of the previous clinical attempts were performed under relatively adverse circumstances: the patients were often debilitated, infected, with multisystem problems, ventilated and even on ECMO. It was believed that results could be improved by careful patient selection; those with limited life expectancy were certainly suitable candidates, but they should not yet have become hospital-dependent or ventilator-dependent.

On March 9, 1981 Bruce Reitz and his colleagues at Stanford University performed the fourth HLTx (Figure 6). This patient was the first long-term survivor, thanks to the improved surgical technique and the use of cyclosporine. The patient was a 45-year old woman with primary pulmonary hypertension (PPH). She suffered two acute rejection episodes successfully reversed, with a good lung function preserved for a long time (35). Two more patients underwent the same operation during the following 4 months (34).

The selection of candidates for single-lung transplantation (SLTx) was much more difficult. The group in Toronto believed (Figure 7) that idiopathic pulmonary fibrosis (IPF) was the ideal disease; these patients generally do not have pulmonary sepsis; furthermore, the reduced compliance and the increased vascular resistance of the native, fibrotic lung would help ensure that ventilation and blood flow (perfusion) will be diverted to the transplanted lung after SLTx.

In 1983, a 58-year-old patient with IPF with the above mentioned characteristics inquired for the possibility of a transplant in Toronto. He was on oxygen 24 hours a day with a limited life expectancy. He underwent right lung transplantation on November 7, 1983; the omentum was transposed into the chest and wrapped around the bronchial anastomosis and tacked to itself. At that time the vascular anastomoses were performed before suturing the bronchus, in order to reduce the ischemic time. He was discharged in 6 weeks and returned to work in 3 months. He died more than 7 years later of renal failure (36). The group at Freeman Hospital in Newcastle-upon-Tyne, U.K. followed the path shown by the Toronto group and reported similar good outcome in patients with pulmonary fibrosis (37).

At that time there were two other axioms that were 

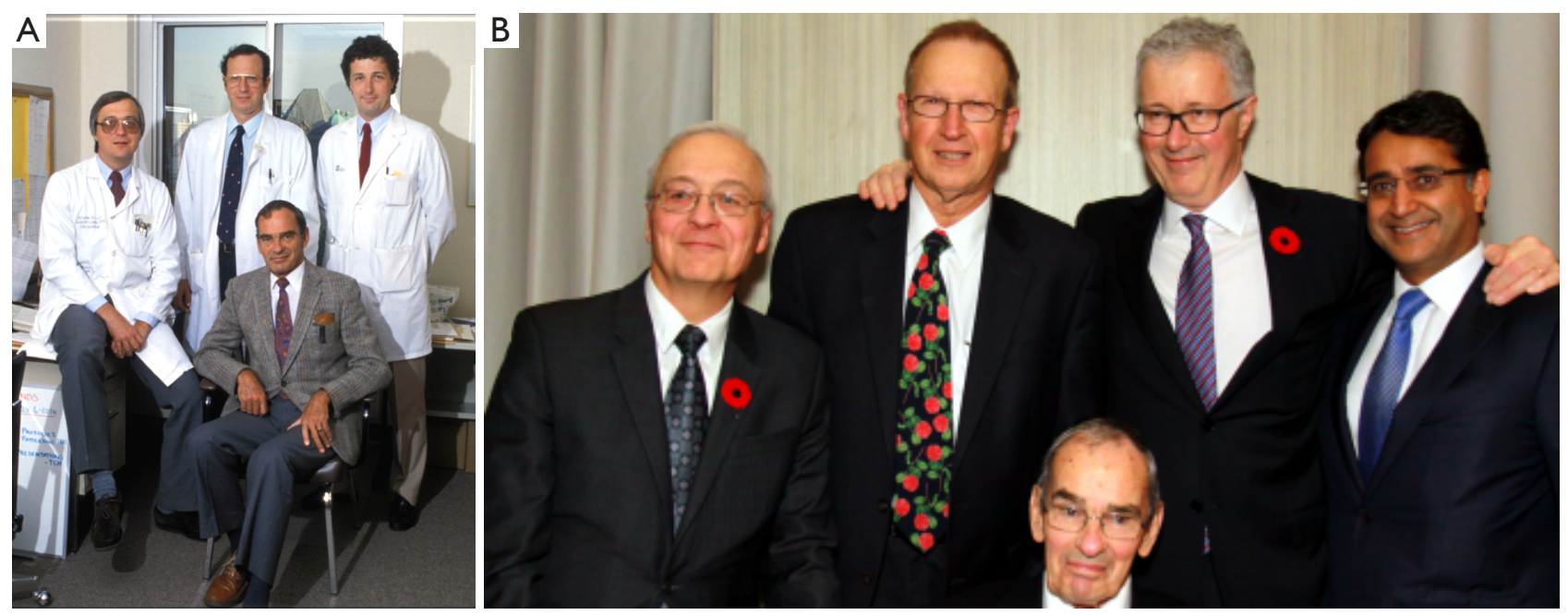

Figure 7 The first long-term success after isolated lung transplantation in patient Tom Hall was performed by the Toronto Lung Transplant Group, Toronto, Ontario, Canada on November 7, 1983 (36). (A) Picture taken in 1987. Surgeons depicted: standing (from left to right): Thomas R. Todd, Joel D. Cooper, G. Alexander Patterson; sitting: F. Griffith Pearson; (B) The Toronto Lung Transplant Group at the $30^{\text {th }}$ anniversary celebration of the first long-term success after single-lung transplantation. The group is now headed by Shaf Keshavjee (same surgeons as depicted in A with Shaf Keshavjee standing fare right (pictures available at http://www.imsmagazine.com/pioneering-lungtransplantation-in-toronto/, accessed August 8, 2017).

subsequently unhitched: (I) SLTx in patients with chronic obstructive pulmonary disease (COPD) was considered not feasible due to concern related to the potential overinflation of the contralateral lung with displacement of the mediastinum toward the transplanted lung; (II) patients with pulmonary sepsis required HLTx, since isolated transplantation of both lungs without the heart was not yet technically feasible.

Cooper and his colleagues believed that most of the patients with septic lung disease have adequate or recoverable right heart function and, at least theoretically, they do not require replacement of the heart. This was confirmed by the pathological reports on the heart removed at that center during HLTx, supporting the idea that the morphology and the function of the heart was preserved. Inclusion of the heart as part of the transplantation procedure was mandated primarily for technical reasons and not because of physiologic necessity. Further confirmation of this feeling came by the "domino" procedure subsequently performed at many centers: the native heart removed from the lung recipient at the time of HLTx was then allotransplanted in another patient with heart failure with excellent postoperative function $(38,39)$. However, at that time HLTx was considered the procedure of choice also to preserve airway vascularization after tracheal anastomosis as small branches of the coronary circulation through the pericardium supply the subcarinal bronchial vessels and maintain tracheal circulation.

Further experiments were conducted to evaluate the possibility to perform isolated bilateral lung transplantation; simultaneous bilateral lung transplantation was proposed by Grosjean and coauthors $(40,41)$. En bloc doublelung transplantation (DLTx) was initially proposed by Vanderhoeft and coworkers in 1972 (42). The experimental activity was initially performed in dogs; however, these animals are unable to breathe after bilateral pulmonary denervation; thus, primate models were required. Feasibility of simultaneous double-lung transplantation was demonstrated in primates in the laboratory at the University of Toronto (43), and it was subsequently performed, on November 26, 1986, in a 42-year old patient with endstage emphysema (44). The procedure was conducted through median sternotomy, under cardioplegic arrest and full cardiopulmonary bypass, with a tracheal anastomosis wrapped with the transposed omentum, an anastomosis between the donor atrial cuff and the back of the recipients' left atrium, and an anastomosis between the main pulmonary artery of the donor and the recipient. It was a technically demanding procedure. Furthermore, further experience with this procedure demonstrated a significant 
incidence of airway complications at the level of the tracheal anastomosis (45). For this reason, during the following years, the procedure was progressively simplified. To avoid problems with tracheal anastomosis, research on bronchial artery revascularization was conducted (46) and several attempts were clinically performed in Copenhagen (47), Bordeaux (48), and later in Cleveland (49), but the technique never gained wide acceptance worldwide. Michel Noirclerc in Marseille (50) proposed to move the tracheal anastomosis to the level of the main bronchi. To avoid the need for CPB, reduce surgical trauma, and improve results, the Group in $\mathrm{St}$ Louis, with Joel Cooper, Alec Patterson and Michael Pasque performed double-lung transplantation as two separate sequential single-lung transplant $(51,52)$. They used the oldfashioned clamshell incision (bilateral thoracosternotomy) to enter both pleural cavities simultaneously, transplanting first on the side of the worst lung. Bisson \& Bonette in Paris developed this bilateral procedure at the same time (53). The clamshell incision was progressively abandoned at most of the centers because of problems with wound healing, and substituted by two anterolateral thoracotomies, avoiding sternal transection $(54,55)$.

At the same time when improved techniques for bilateral lung transplantation (BLTx) were developed, the indications for SLTx expanded. After the initial report from the group of Andreassian in France (56-58), SLTx has been successfully performed in patients with emphysema by other groups $(59,60)$.

In the mid-1990s SLTx was used for a selected group of patients with PPH. This procedure was encouraged by previous reports from a similar patient population: patients with pulmonary hypertension undergoing thromboendarterectomy for chronic pulmonary embolism had favorable hemodynamic response despite compromised preoperative right ventricular function (61). Experimental studies supported this idea (62). The successful clinical experience of the group in St Louis confirmed the value of the procedure $(63,64)$, although sequential BLTx was subsequently considered a better option compared to SLTx for patients with pulmonary vascular disease to avoid lifethreatening complications resulting in early (reperfusion edema) and late (bronchiolitis obliterans) graft dysfunction and also compared to HLTx because of the critical shortage for donor hearts (65).

\section{Intraoperative cardiopulmonary support}

Cardiopulmonary support is often needed in lung transplantation, especially in patients with pulmonary hypertension or with disturbances in gas exchange upon clamping of the first native lung prior to extraction (severe hypoxia or inappropriate ventilation). Historically, conventional cardiopulmonary bypass $(\mathrm{CPB})$ was used to circumvene these intra-operative problems and is still used by many lung transplant centers worldwide. Discussion on the need for routine use of $\mathrm{CPB}$ is still ongoing $(66,67)$. More recently, a shift has been noticed towards the use of veno-arterial extracorporeal membrane oxygenation ( $\mathrm{V}-\mathrm{A}$ ECMO) to decompress the right ventricular preload and to improve gas exchange intraoperatively. The advantages of V-A ECMO over CPB are the reduced need for anticoagulation with less bleeding and a lower inflammatory response resulting in less postoperative complications. The Vienna group was the first to describe the use of V-A ECMO for intra-operative support (68). Many more groups worldwide have now switched from CPB to V-A ECMO with superior early outcomes reported (69-72).

\section{The future is here}

Many problems still need to be solved. During the last decade, the number of transplants around the world remained substantially stable after a previous exponential increase (73). This was mainly related to the limited availability of suitable organs for transplantation. For this reason extended-criteria donors not fulfilling the standard criteria are increasingly being used (74-76). However, there are other means to increase the total number of lung donors:

(I) Living-related transplants;

(II) Lungs from donation after circulatory death donors (DCD's);

(III) Ex vivo evaluation and reconditioning of previously unsuitable donor lungs.

\section{Living-related lung transplantation}

Living-donor lobar lung transplantation (LDLLT) was successfully introduced by Vaughn Starnes and his colleagues at the University of Stanford in the late 1990 (77). The first procedure was performed transplanting a mother's right upper lobe to her 12-year old daughter born with bronchopulmonary dysplasia and the patient survived. The second patient was a 3 -year old girl with Eisenmenger's syndrome. Starnes performed again a right single-lobe transplant using the middle lobe of his father and he also closed the ventricular septal defect. 
Unfortunately this second patient died of primary graft dysfunction. After this unsuccessful experience, the group switched to bilateral LDLLT, harvesting the lower lobes from two healthy living donors $(78,79)$. The small volume of the two transplanted lobes encouraged to perform this procedure only in children, at least at the beginning of the historical experience; it was applied almost exclusively to cystic fibrosis patients (80). However, it is now recognized that it can be applied also to patients with obstructive, restrictive, infectious and hypertensive lung disease, both in the pediatric and adult population given an acceptable size matching $(81,82)$. Although LDLLT was initially proposed in the United States, the number of cases performed in that country progressively decreased due to the changes of organ sharing favoring an urgency benefit for allocation of cadaveric organs. For this reason, reports of LDLLT came almost exclusively from Japan, where the average waiting time for a cadaveric lung is more than 2 years (82). Other small series were published from Brazil (83) and China (84). Overall, the results of LDLLT are equal if not better than conventional cadaveric lung transplantation (85). Currently, the group at Kyoto University led by H. Date is continuing to pioneer this procedure with excellent results in a difficult group of patients.

\section{Lungs from donation after circulatory death donors (DCD's)}

The very first lung transplantation in humans by James Hardy in 1963 was performed with a pulmonary graft coming from a donor who died after myocardial infarction (17). The donor lung therefore was first subjected to a period of warm ischemia prior to topical cooling. After acceptance of the Harvard criteria on brain death (86), the practice of using organs from donors dying from cardiocirculatory arrest (DCD's), previously called non-heart-beating donors (NHBD's) (87), was largely abandoned. Following an international workshop organized on 30-31 March 1995 by Kootstra in Maastricht, the Netherlands, different categories of DCD's have been recognized based on the so called Maastricht classification (88).

The concept of lung transplantation from DCD's was reintroduced by Thomas M. Egan (Chapel Hill, NC, USA) in 1991 following a series of dog experiments (89). This concept was based on the fact that lung tissue may remain viable for a certain period after death as a result of the oxygen reserve present in the alveoli. His work has stimulated many research groups worldwide to explore the possibility of transplanting lungs from donors after circulatory arrest (90).

In 1995, Robert Love (Madison, WI) reported a successful first case report following transplantation of a single lung from a controlled DCD (91). In 2001, Stig Steen (Lund, Sweden) reported a remarkable case of successful SLTx from an uncontrolled DCD after pretransplant ex vivo perfusion for functional evaluation (92). Most reported series on DCD lung transplantation nowadays come from groups retrieving organs from donors with severe brain damage after withdrawal of life support (DCD Maastricht Category III). Short and long-term outcome in lung recipients from such donors have been reported to be equal to brain-dead donors in experienced centers (93). This was confirmed in a recent meta-analysis of reported observational cohort studies (94) and in a published collective series of 306 transplants submitted to the International Society for Heart and Lung Transplantation DCD Registry (95). The group headed by A. Varela in Madrid, Spain reported in 2004 two successful lung transplants from uncontrolled DCD's (Maastricht Categories I and II) after failed resuscitation in the donor (96). In subsequent papers, the incidence of primary graft dysfunction grade 3 was reported to be higher with lower short-term survival in these recipients. This underlines the need to evaluate pulmonary graft performance with the use of ex vivo lung perfusion (EVLP) prior to transplantation (97). The world's experience with uncontrolled donors so far remains anecdotal with successful case reports by individual centers only $(98,99)$.

\section{Ex vivo evaluation and reconditioning of previously unsuitable lungs}

As previously mentioned, Stig Steen in Lund, Sweden was the first to report a successful case of SLTx from a DCD after $e x$ vivo evaluation of the pulmonary graft (92). Steen introduced the concept of EVLP as a method, not only to evaluate more objectively lung performance prior to transplantation, but also as a possible technique to revitalize donor lungs of inferior quality outside the body previously regarded as unusable for transplantation (100). This new technique may open new perspectives in the field of lung transplantation in the future (101).

Early attempts to perfuse lungs were complicated by edema formation and deterioration of pulmonary function $(102,103)$. A fundamental step towards success was the development of Steen Solution ${ }^{\mathrm{TM}}$, a buffered perfusate with high albumine concentration to create an ideal colloid 
osmotic pressure of about $30 \mathrm{mmHg}$ allowing physiologic perfusion pressures and flow to be maintained without the development of either tissue edema or dehydration (104). Clinical EVLP was pioneered by the groups in Lund and Toronto. A first prospective clinical case series (HELP trial) was published in a landmark publication by Cypel and Keshavjee from Toronto in 2011 showing non-inferiority for PGD and 30-day mortality in 20 EVLP lung transplant recipients compared to 116 contemporaneous standard lung transplants performed in their center (105). Since then, many other groups around the world have reported similar experience with transplantation of EVLP lungs initially rejected for transplantation with a utilization rate between $39-100 \%$ (101). EVLP nowadays is becoming a standard technique for better assessment of questionable lungs from extended-criteria donors and from DCD's with uncertainty about their post-transplant function (106). The outcome in EVLP lung recipients is now further investigated in prospective clinical trials (NOVEL trial, EXPAND trial). Anecdotal case reports were published on successful transplantation of previously unacceptable and injured lungs after drug treatment during EVLP (107-109). If longer perfusion times (>12-24 hours) would prove to be possible, repair of injured grafts by delivered therapies interacting via several mechanisms could be investigated. Several treatment pathways have been suggested including the administration of infused or inhaled drugs, gases, and stem cell therapy (110). Further research is needed in order to maximize the yield of donor lungs for transplantation. Hopefully one day we will be able to repair pulmonary allografts in a box to become "brand-new lungs" prior to implantation (111).

Different protocols and techniques for static EVLP have been described and several commercial EVLP devices have now become available for clinical use (101). In addition, when the final results of the Inspire trial prove to be favourable, dynamic normothermic EVLP with a portable device may become a new preservation method for standard donor lungs thereby reducing the cold ischemic period and safely prolonging the cross clamp time making the transplantation process a better planned procedure (112).

\section{Conclusions}

Lung transplantation has come a long way since the first human lung transplantation by J Hardy in 1963 and the first clinical successes in the early eighties. After more than fifty years of clinical experience, lung transplantation in many experienced centers across the world has now become a standard and routine procedure for patients with end-stage lung disease with no other treatment options available. Better early and late survival observed over the years is multifactorial and is expected to further improve in the third millennium. History will learn whether we will be able to overcome the persistent hurdles of donor organ shortage and chronic lung allograft dysfunction. Hope remains that recipient morbidity resulting from life-long immunosuppressive therapy one day will be overcome with immunomodulatory techniques resulting in better tolerance of the allograft.

\section{Acknowledgements}

None.

\section{Footnote}

Conflicts of Interest: The authors have no conflicts of interest to declare.

\section{References}

1. Carrel A. The surgery of blood vessels. Johns Hopkins Hosp Bull 1907;18:18-28.

2. Demikhov VP. Transplantation of the heart, lungs and other organs. Eksp Khir Anesteziol 1969;14:3-8.

3. Becerra E, Kaplan J, Cooper DKC. Experimental background and early clinical experience. In: The transplantation and replacement of thoracic organs. Ed Cooper DKC and Novitzky D. Dordrecht/Boston/ London: Kluwer Academic Publishers, 1990;Cap 33:261-72.

4. Robicsek F, Pruitt JR, Sanger PW, et al. The maintenance of function of the donor heart in the extracorporeal stage and during transplantation. Ann Thorac Surg 1968;6:330-42.

5. Marcus E, Wong SN, Luisada AA. Homologous heart grafts: transplantation of the heart in dogs. Surg Forum 1951;2:212-7.

6. Marcus E, Wong SN, Luisada AA. Homologous heart grafts. I: Technique of interim parabiotic perfusion. II: Transplantation of the heart in dogs. AMA Arch Surg 1953;66:179-91.

7. Staudacher VE, Bellinazzo P, Pulin A. Primi rilievi su tentativi di reimpianti autoplasici e di trapianti omoplasici di lobi polmonari. Chirurgia 1950;5:223-8.

8. Matejicek E. Transplantation of organs. Transplant Bull 
1956;3:167.

9. Metras H. Note preliminaire sur greffe totale du poumon chez le chien. Comp Renal Acad Sci 1950;231:1176-7.

10. Juvenelle AA, Citret C, Wiles CE, et al. Pneumonectomy with the reimplantation of the lung in the dog for physiologic study. J Thorac Surg 1951;21:111-5.

11. Neptune WB, Weller R, Baily CP. Experimental lung transplantation. J Thorac Surg 1953;26:275-89.

12. Howard HS, Webb WR. Respiratory paralysis following pulmonary denervation. Surg Forum 1957;8:466-9.

13. Webb WR, Howard HS. Cardiopulmonary transplantation. Surg Forum 1957;8:313-7.

14. Hardin CA, Kittle CF. Experience with transplantation of the lung. Science 1954;119:97-8.

15. Blumenstock DA, Kahan DR. Replantation and transplantation of the canine lung. J Surg Res 1961;1:40-7.

16. Hardy JD. Cap 45: Experimental background and early clinical experience. In: Cooper DK, Novitzky D. editors. The Transplantation and Replacement of Thoracic Organs. Dordrecht: Springer, 1990:357-61.

17. Hardy JD, Webb WR, Dalton ML Jr, et al. Lung homotransplantation in man. JAMA 1963;186:1065-74.

18. Hardy JD, Araslan S, Webb WR. Transplantation of the lung. Ann Surg 1964;160:440-8.

19. Cooley DA, Bloodwell RD, Hallman GL, et al. Organ transplantation for advanced cardiopulmonary disease. Ann Thorac Surg 1969;8:30-46.

20. Wildevuur CR, Benfield JR. A review of 23 human lung transplantations by 20 surgeons. Ann Thorac Surg 1970;9:489-515.

21. Losman JG, Campbell CD, Reploge RL, et al. Joint transplantation of the heart and the lungs. Past experience and present potentials. J Cardiovasc Surg (Torino) 1982;23:440-52.

22. Barnard CN, Cooper DKC. Clinical transplantation of the heart: a review of 13 years personal experience. J Roy Soc Med 1981;74:670-4.

23. Cooper JD. Lung transplantation. Ann Thorac Surg 1989;47:28-44.

24. Wildevuur CRH, Benfield JR. A review of 23 human lung transplantations by 20 surgeons. Ann Thorac Surg 1970;9:489-515.

25. Derom F, Barbier F, Ringoir S, et al. Ten month survival after lung transplantation in man. J Thorac Cardiovasc Surg 1971;61:835-46.

26. Venuta F, Van Raemdonck D. A right single-lung transplantation performed by Prof. em Dr. Fritz Derom at the University Hospital in Ghent, Belgium on 14th
November 1968 in patient Aloïs Vereecken who suffered from end-stage lung fibrosis (silicosis resulting from professional sand-blasting). Asvide 2017;4:583. Available online: http://www.asvide.com/articles/1908

27. Nelems JM, Rebuck AS, Cooper JD, et al. Human lung transplantation. Chest 1980;78:569-73.

28. Nelems JM, Duffin J, Glynn F, et al. Extracorporeal membrane oxygenator support for human lung transplantation. J Thorac Cardiovasc Surg 1978;76:28-32.

29. Lima O, Cooper JD, Peters WJ, et al. Effects of methylprednisolone and azathioprine on bronchial healing following lung autotransplantation. J Thorac Cardiovasc Surg 1981;82:211-5.

30. Goldberg M, Lima O, Morgan E, et al. A comparison between cyclosporine A and methylprednisolone plus azathioprine on bronchial healing following canine lung allotransplantation. J Thorac Cardiovasc Surg 1983;85:821-6.

31. Saunders NR, Egan TM, Chamberlain D, et al. Cyclosporine and bronchial healing in canine lung transplantation. J Thorac Cardiovasc Surg 1984;88:993-9.

32. Dubois P, Choiniere L, Cooper JD. Bronchial omentopexy in canine lung allotransplantation. Ann Thorac Surg 1984;38:211-4.

33. Morgan E, Lima O, Goldberg M, et al. Successful revascularization of totally ischaemic bronchial autografts in dogs using omental pedicle flaps. J Thorac Cardiovasc Surg 1982;84:204-10.

34. Reitz BA, Wallwork J, Hunt SA, et al. Heart and lung transplantation: successful therapy for patients with pulmonary vascular disease. N Engl J Med 1982;306:557-64.

35. Reitz BA, Pennock JL, Shumway NE. Simplified operative method for heart and lung transplantation. J Surg Res 1981;31:1-5.

36. Toronto Lung Transplant Group: unilateral lung transplantation for pulmonary fibrosis. N Engl J Med 1986;314:1140-5.

37. McGregor CG, Dark JH, Hilton CJ, et al. Early results of single lung transplantation in patients with endstage pulmonary fibrosis. J Thorac Cardiovasc Surg 1989;98:350-4.

38. Shudo Y, Ma M, Boyd JH, et al. Current status of domino heart transplantation. J Card Surg 2017;32:229-32.

39. Cooper JD. Dominoes - pragmatism or piracy? Transpl Int 1991;4:1-2.

40. Grosjean O, Noirclerc M, Duvinage JF, et al. Bilateral lung transplantation. Preliminary report. Acta Chir Belg 
1972;Suppl 2:49-55.

41. Grosjean O, Noirclerc M, Mattei M, et al P. One-stage bilateral allogenic pulmonary transplantation. Ann Chir Thorac Cardiovasc 1973;12:105-8.

42. Vanderhoeft P, Dubois A, Lauvau N, et al. Block allotransplantation of both lungs with pulmonary artery trunk and left atrium in dogs. Thorax 1972;27:415-9.

43. Dark JH, Patterson GA, Al-Jilaihawi AN, et al. Experimental en bloc double-lung transplantation. Ann Thorac Surg 1986;42:394-8.

44. Patterson GA, Cooper JD, Dark JH, et al. Experimental and clinical double lung transplantation. J Thorac Cardiovasc Surg 1988;95:70-4.

45. Patterson GA, Todd TR, Cooper JD, et al. Airway complications after double lung transplantation. J Thorac Cardiovasc Surg 1990;99:14-20.

46. Schreinemakers HH, Weder W, Miyoshi S, et al. Direct revascularization of bronchial arteries for lung transplantation: an anatomical study. Ann Thorac Surg 1990;49:44-53.

47. Pettersson G, Arendrup H, Mortensen SA, et al. Early experience of double-lung transplantation with bronchial artery revascularization using mammary artery. Eur J Cardiothorac Surg 1994;8:520-4.

48. Couraud L, Baudet E, Nashef SA, et al. Lung transplantation with bronchial revascularization. Surgical anatomy, operative technique and early results. Eur J Cardiothorac Surg 1992;6:490-5.

49. Tong MZ, Johnston DR, Pettersson GB. The role of bronchial artery revascularization in lung transplantation. Thorac Surg Clin 2015;25:77-85.

50. Noirclerc MJ, Metras D, Vaillant A, et al. Bilateral bronchial anastomosis in double lung and heart-lung transplantations. Eur J Cardiothorac Surg 1990;4:314-7.

51. Pasque MK, Cooper JD, Kaiser LR, et al. Improved results for bilateral lung transplantation: rationale and initial experience. Ann Thorac Surg 1990;49:785-91.

52. Kaiser LR, Pasque MK, Trulock EP, et al. Bilateral sequential lung transplantation: the procedure of choice for double-lung replacement. Ann Thorac Surg 1991;52:438-45.

53. Bisson A, Bonette P. A new technique for double lung transplantation. "Bilateral single lung" transplantation. J Thorac Cardiovasc Surg 1992;103:40-6.

54. Taghavi S, Birsan T, Pereszlenyi A, et al. Bilateral lung transplantation via two sequential anterolateral thoracotomies. Eur J Cardiothorac Surg 1999;15:658-62.

55. Venuta F, Rendina EA, De Giacomo T, et al. Bilateral sequential lung transplantation without sternal division. Eur J Cardiothorac Surg 2003;23:894-7.

56. Mal H, Andreassian B, Pamela F, et al. Unilateral lung transplantation in end-stage pulmonary emphysema. Am Rev Respir Dis 1989;140:797-802.

57. Mal H, Andreassian B, Pariente R. Single lung transplantation in hyperinflated patients. Chest 1990;97:110S-111S.

58. Sleiman C, Mal H, Andreassian B, et al. Single lung transplantation in pulmonary emphysema. N Engl J Med 1990;323:551-2.

59. Klepetko W, Grimm M, Laufer G, et al. One and onehalf year experience with unilateral and bilateral lung transplantation. J Card Surg 1992;7:126-33.

60. Van Raemdonck D, Verleden G, Coosemans W, et al. Isolated lung transplantation; initial experience at the University Hospitals Leuven. Leuven Lung Transplant Group. Acta Chir Belg 1994;94:245-57.

61. Moser KM, Daily PO, Peterson K, et Al. Thromboendarterectomy for chronic, major vessel thromboembolic pulmonary hypertension: immediate and long term results. Ann Intern Med 1987;107:560-5.

62. Hsieh CM, Mishkel G, Radowski H, et al. Production and reversibility of right ventricular hypertrophy and right heart failure in dogs. Ann Thorac Surg 1992;54:104-10.

63. Pasque MK, Kaiser LR, Dresler CM, et al. Single lung transplantation for pulmonary hypertension. J Thorac Cardiovasc Surg 1992;103:475-81; discussion 481-2.

64. Pasque MK, Trulock EP, Cooper JD, et al. Single lung transplantation for pulmonary hypertension. Single institution experience in 34 patients. Circulation 1995;92:2252-8.

65. Birsan T, Zuckermann A, Artemiou O, et al. Functional results and long-term outcome after bilateral lung transplantation for pulmonary hypertension. Wien Klin Wochenschr 1998;110:45-52.

66. Marczin N, Royston D, Yacoub M. Pro: lung transplantation should be routinely performed with cardiopulmonary bypass. J Cardiothorac Vasc Anesth 2000;14:739-45.

67. McRae K. Con: lung transplantation should not be routinely performed with cardiopulmonary bypass. J Cardiothorac Vasc Anesth 2000;14:746-50.

68. Pereszlenyi A, Lang G, Steltzer H, et al. Bilateral lung transplantation with intra- and postoperatively prolonged ECMO support in patients with pulmonary hypertension. Eur J Cardiothorac Surg 2002;21:858-63.

69. Ius F, Kuehn C, Tudorache I, et al. Lung transplantation 
on cardiopulmonary support: venoarterial extracorporeal membrane oxygenation outperformed cardiopulmonary bypass. J Thorac Cardiovasc Surg 2012;144:1510-6.

70. Biscotti M, Yang J, Sonett J, et al. Comparison of extracorporeal membrane oxygenation versus cardiopulmonary bypass for lung transplantation. J Thorac Cardiovasc Surg 2014;148:2410-5.

71. Bermudez CA, Shiose A, Esper SA, et al. Outcomes of intraoperative venoarterial extracorporeal membrane oxygenation versus cardiopulmonary bypass during lung transplantation. Ann Thorac Surg 2014;98:1936-42; discussion 1942-3.

72. Machuca TN, Collaud S, Mercier O, et al. Outcomes of intraoperative extracorporeal membrane oxygenation versus cardiopulmonary bypass for lung transplantation. J Thorac Cardiovasc Surg 2015;149:1152-7.

73. Christie JD, Edwards LB, Kucheryavaya AY, et al. The registry of the International Society for Heart and Lung Transplantation: 27th official adult lung and heart lung transplant report--2010. J Heart Lung Transplant 2010;29:1104-18.

74. Schiavon M, Falcoz PE, Santelmo N, at al. Does the use of extended criteria donors influence early and long term results of lung transplantation? Interact Cardiovasc Thorac Surg 2012;14:183-7.

75. Meers C, Van Raemdonck D, Verleden GM, et al. The number of lung transplants can be safely doubled using extended criteria donors; a single-center review. Transpl Int 2010;23:628-35.

76. Somers J, Ruttens D, Verleden SE, et al. A decade of extended-criteria lung donors in a single center: was it justified? Transpl Int 2015;28:170-9.

77. Starnes VA, Lewiston NJ, Luikart H, et al. Current trends in lung transplantation: lobar transplantation and expanded use of single lungs. J Thorac Cardiovasc Surg 1992;104:1060-5; discussion 1065-6.

78. Starnes VA, Barr ML, Cohen RG. Lobar transplantation: indications, technique and outcome. J Thorac Cardiovasc Surg 1994;108:403-10.

79. Starnes VA, Barr ML, Cohen RG, et al. Living - donor lobar transplantation experience: intermediate results. J Thorac Cardiovasc Surg 1996;112:1284-90.

80. Starnes VA, Barr ML, Schenkel FA, et al. Experience with living - donor lobar lung transplantation for indications other than cystic fibrosis. J Thorac Cardiovasc Surg 1997;114:917-21.

81. Date H, Aoe M, Nagahiro I, et al. Living - donor lobar lung transplantation for various lung diseases. J Thorac
Cardiovasc Surg 2003;126:476-81.

82. Date H, Aoe M, Sano Y, et al. Improved survival after living - donor lobar transplantation. J Thorac Cardiovasc Surg 2004;128:933-40.

83. Camargo SM, Camargo JJP, Schio SM, et Al. Complications related to lobectomy in living lobar lung transplant donors. J Bras Pneumol 2008;34:256-63.

84. Chen QK, Jiang GN, Ding JA, et al. First successful bilateral living - donor lobar lung transplantation in China. Chin Med J 2010;123:1477-78.

85. Date H, Sato M, Aoyama A, et al. Living donor lobar lung transplantation provides similar survival to cadaveric lung transplantation even for very ill patients. Eur J Cardiothorac Surg 2015;47:967-72.

86. A definition of irreversible coma: report of the Ad Hoc Committee of the Harvard Medical School to Examine the Definition of Brain Death. JAMA 1968;205:337-40.

87. Kootstra G, Kievit J, Nederstigt A. Organ donors: heartbeating and non-heart beating. World J Surg 2002; 26:181-4.

88. Kootstra G, Daemen JH, Oomen AP. Categories of nonheart-beating donors. Transplant Proc 1995;27:2893-4.

89. Egan T, M, Lambert CJ, Reddick R, et al. A strategy to increase the donor pool: use of cadaver lungs for transplantation. Ann Thorac Surg 1991;52:1113-20.

90. Van Raemdonck DE, Rega FR, Neyrinck AP, et al. Nonheart-beating donors. Semin Thorac Cardiovasc Surg. 2004;16:309-21.

91. Love RB, Stringham JC, Chomiak PN, et al. Successful lung transplantation using a non-heart-beating donor. J Heart Lung Transplant 1995;14:S88.

92. Steen S, Sjöberg T, Pierre L, et al. Transplantation of lungs from a non-heart-beating donor. Lancet 2001;357:825-9.

93. Ruttens D, Martens A, Ordies S, et al. Short- and LongTerm Outcome After Lung Transplantation From Circulatory-Dead Donors: A Single-Center Experience. Transplantation 2017;101:2691-4.

94. Krutsinger D, Reed RM, Blevins A, et al. Lung transplantation from donation after cardiocirculatory death: a systematic review and meta-analysis. J Heart Lung Transplant 2015;34:675-84.

95. Cypel M, Levvey B, Van Raemdonck D, et al. International Society for Heart and Lung Transplantation Donation After Circulatory Death Registry Report. J Heart Lung Transplant 2015;34:1278-82.

96. Nuñez JR, Varela A, del Rio F, et al. Bipulmonary transplants with lungs obtained from two non-heartbeating donors who died out of hospital. J Thorac 
Cardiovasc Surg 2004;127:297-9.

97. Gomez-de-Antonio D, Campo-Cañaveral JL, Crowley S, et al. Clinical lung transplantation from uncontrolled nonheart-beating donors revisited. J Heart Lung Transplant 2012;31:349-53.

98. Suzuki Y, Tiwari JL, Lee J, et al. Should we reconsider lung transplantation through uncontrolled donation after circulatory death? Am J Transplant 2014;14:966-71.

99. Valenza F, Citerio G, Palleschi A, et al. Successful Transplantation of Lungs From an Uncontrolled Donor After Circulatory Death Preserved In Situ by Alveolar Recruitment Maneuvers and Assessed by Ex Vivo Lung Perfusion. Am J Transplant 2016;16:1312-8.

100. Steen S, Liao Q, Wierup PN, et al. Transplantation of lungs from non-heart-beating donors after functional assessment ex vivo. Ann Thorac Surg 2003;76:244-52.

101. Van Raemdonck D, Neyrinck A, Cypel M, et al. Ex-vivo lung perfusion. Transpl Int 2015;28:643-56.

102. Jirsch DW, Fisk RL, Couves CM. Ex vivo evaluation of stored lungs. Ann Thorac Surg 1970;10:163-8.

103. Sanchez PG, Bittle GJ, Burdorf L, et al. State of art: clinical ex-vivo lung perfusion: rationale, current status, and future directions. J Heart Lung Transplant 2012;31:339-48.

104. Lindstedt S, Eyjolfsson A, Koul B, et al. How to recondition ex vivo initially rejected donor lungs for clinical transplantation: clinical experience from the Lund university hospital. J Transplant 2011;2011:754383.

Cite this article as: Venuta F, Van Raemdonck D. History of lung transplantation. J Thorac Dis 2017;9(12):5458-5471. doi: $10.21037 /$ jtd.2017.11.84
105. Cypel M, Yeung JC, Liu M, et al. Normothermic ex vivo lung perfusion in clinical lung transplantation. $\mathrm{N}$ Engl J Med 2011;364:1431-40.

106. Machuca TN, Mercier O, Collaud S, et al. Lung transplantation with donation after circulatory determination of death donors and the impact of ex vivo lung perfusion. Am J Transplant 2015;15:993-1002.

107. Wigfield CH, Cypel M, Yeung J, et al. Successful emergent lung transplantation after ex vivo perfusion optimization and transportation of donor lungs. Am J Transplant 2012;12:2838-44.

108. Machuca TN, Hsin MK, Ott HC, et al. Injury-specific ex vivo treatment of the donor lung: pulmonary thrombolysis followed by successful lung transplantation. Am J Respir Crit Care Med 2013;188:878-80.

109. Inci I, Yamada Y, Hillinger S, et al. Successful lung transplantation after donor lung reconditioning with urokinase in an ex-vivo lung perfusion system. Ann Thorac Surg 2014;98:1837-8.

110. Cypel M, Keshavjee S. Extending the donor pool: rehabilitation of poor organs. Thorac Surg Clin 2015;25:27-33.

111. Ordies S, Neyrinck A, Van Raemdonck D. Can we make recovered donor lungs look brand-new again? Eur J Cardiothorac Surg 2017;52:178-9.

112. Warnecke G, Van Raemdonck D, Kukreja J, et al. Mid and long-term clinical results of OCS Lung Inspire International trial. J Heart Lung Transplant 2016;35:S15-16. 